\title{
Monocyte counting: Discrepancies in results obtained with different automated instruments
}

\author{
W Goossens, L Van Hove, R L Verwilghen
}

\begin{abstract}
To determine the accuracy of several methods for measuring the monocyte count, the results obtained by a number of different automated cell counters were analysed. Considerable discrepancies occurred for monocyte counts obtained in normal blood among the counters. The results of a visual monocyte count on a total of 800 leucocytes were used as the reference method. The technique of measuring the monocyte count by using dual staining with monoclonal antibodies CD45 and CD14 provided the closest agreement with the reference method. Six other automated counting systems were assessed. Two of these systems (Coulter VCS and Technicon H1) gave results, which, although underestimating monocytosis, correlated well with the results obtained by the reference technique. A third system (Toa Sysmex NE-8000) gave unreliable results. Three of the automated systems evaluated measured a "third population"-that is, monocytes together with other leucocytes. One of these systems (Ortho ELT 1500), overestimated the count; as expected, but correlated well with the reference method. The second of these "third population counters" (Coulter S Plus IV) correlated moderately well with the reference monocytosis, while the Toa Sysmex E-5000 correlated poorly.

It is clear that problems exist in the evaluation of different instruments for counting monocytes. An accurate and reliable reference method is a prerequisite to evaluate this aspect of cell counters. As the visual method is too cumbersome a different reference method would be useful. Based on the results of this study, it is suggested that the technique using fluorescence labelled monoclonal antibodies should be regarded as an acceptable alternative.
\end{abstract}

Department of Haematology, University Hospital Gasthuisberg, B3000 Leuven, Belgium W Goossens L Van Hove L Lan Hove
L Verwilghen Correspondence to: Dr Goossens 6 September 1990
As a centre involved in the quality assessment of haematological procedures, we evaluated different automated cell analysers. There was good correlation among instruments as regards measurement of most haematological variables in healthy donors, but major discrepancies were noted in the monocyte counts.

The subpopulations of leucocytes can be identified in different ways. Such techniques include assessment of cell morphology on a routine Romanowsky stain, use of monoclonal antibodies against specific receptors on the cell membrane, detection of specified cytoplasmic enzymes and different physical measurements. These different techniques, used in automated cell counters, reliably identify granulocytes and lymphocytes, but they do not always recognise identical cells as monocytes.

We compared the monocyte count measured in samples of normal blood with the Becton Dickinson FACScan, the Coulter S Plus IV 3diff and Coulter VCS, Ortho ELT 1500, Technicon H1, and the Toa Sysmex E5000 and NE-8000. As the reference method we used the visual leucocyte differential count on Romanowsky stained blood films.

Reliability of the monocyte count can be important for the diagnosis of different diseases. An increased monocyte count is mainly seen in patients with subacute or chronic infection. Such pathology has become rare in western Europe. According to the FAB criteria, however, ${ }^{1}$ the key to the diagnosis of chronic myelomonocytic leukaemia is the presence of more than $1 \times 10^{9}$ monocytes/l.

Prompted by our observations in blood from healthy donors, we will extend our investigations to patients with chronic myeloid monocytic leukaemia (CMML) to determine if our observations in the former group are also relevant to "myelodysplastic" and "leukaemic" monocytes.

\section{Methods}

Blood was taken from healthy adults, mainly from family members of patients treated in the Haematology Department. This was done during a screening procedure for potential donors of bone marrow or thrombocytes to their relatives. The samples were taken on dipotassium EDTA $(1.5 \mathrm{mg} / \mathrm{ml})$, and all procedures were done between 30 minutes and four hours after the sample had been collected. A maximal time interval of one hour was allowed between the different measurements done on an individual blood sample. Results of a given blood count were not used if one of these results was outside the reference range for healthy adults.

Orthogonal regression was used ${ }^{23}$ to evaluate the correlation between our reference method and each of the evaluated instruments. 


\section{REFERENCE METHOD}

The NCCLS recommendation $\mathrm{H} 20-\mathrm{T}$ was followed. ${ }^{4}$ Four smears were made from each blood sample. These were stained with MayGrünwald-Giemsa. ${ }^{5}$ Two hundred cells were counted by each of four experienced technicians. The technicians had been matched against each other and obtained comparable results. Monocytes were identified according to the following criteria:

"the largest normal peripheral blood cell ... with an irregular, often lobulated nucleus and opaque greyish-blue cytoplasm with fine azurophilic granules. The cell outline is often irregular and the cytoplasm may be vacuolated". 6

\section{INSTRUMENTS}

All instruments were used with the reagents recommended by their respective manufacturers. Automated instruments all identify between 8.000 and 15.000 "events" in normal blood.

Becton Dickinson FACScan Whole blood $(100 \mu \mathrm{l})$ was incubated for 15 minutes with $20 \mu \mathrm{l}$ of Leucogate (Becton Dickinson), consisting of a monoclonal antibody combination of CD45-FITC ( anti-leucocyte antibody) and CD14-PE (anti-monocyte antibody). Subsequently the erythrocytes were lysed by the addition of $2 \mathrm{ml}$ of FACS Lysing Solution (Becton Dickinson). Measurement of green and red fluorescence, together with forward and side scatter were used (Simultest).

Coulter S Plus IV 3diff The "third" population (considered by the manufacturers to be mainly monocytes) was counted, measuring the aperture impedance of cells in blood diluted in a slightly hypotonic diluent.

Coulter VCS Leucocytes were identified using a combination of aperture-impedance, conductivity for high frequency radio-waves, and forward and side scatter of laser light in a flow cytometer in an isotonic diluent. The instrument was used in "clinical mode".

Ortho ELT 1500 A "third population containing monocytes" was counted in this cell counter using forward and side scatter of laser light on blood in an hypotonic diluent.

Technicon H1 Monocytes are counted by a combination of light absorption by peroxidase stained cells and forward scatter of laser light.

Toa-Sysmex E-5000 The middle cell ratio (containing, according to the manufacturers, monocytes together with eosinophilic and basophilic granulocytes) was counted, measuring the aperture impedance of cells in blood diluted in a hypotonic diluent.

Toa-Sysmex NE-8000 This instrument uses a combined measurement of aperture impedance and conductivity for high frequency radio-waves on blood in a slightly hypotonic diluent.
Table 1 Precision of monocyte count using different methods, based, for each instrument, on 30 replicate analyses of one blood sample

\begin{tabular}{lccr}
\hline Method & Mean & Range & CV\% \\
\hline Visual count $(4 \times 200$ cells) & $11 \cdot 4$ & $9 \cdot 9-12 \cdot 9$ & $6 \cdot 4$ \\
Becton Dickinson FACScan & $5 \cdot 0$ & $4 \cdot 0-6 \cdot 0$ & $5 \cdot 2$ \\
Coulter VCS & $10 \cdot 28$ & $9 \cdot 2-11 \cdot 2$ & $4 \cdot 8$ \\
Coulter S Plus IV & 10.07 & $7 \cdot 5-12 \cdot 0$ & $11 \cdot 1$ \\
Ortho ELT 1500 & $10 \cdot 44$ & $9 \cdot 8-11.9$ & $3 \cdot 9$ \\
Technicon H1 & $7 \cdot 52$ & $6 \cdot 5-8 \cdot 7$ & $6 \cdot 8$ \\
Toa Sysmex E-5000 & $7 \cdot 34$ & $2 \cdot 0-21 \cdot 3$ & $68 \cdot 1$ \\
Toa Sysmex NE-8000 & $6 \cdot 01$ & $5 \cdot 0-7 \cdot 2$ & $10 \cdot 3$ \\
\hline
\end{tabular}

\section{Results}

The precision of the monocyte count (expressed as a percentage of leucocytes) measured by each of the different technologies was determined by 30 consecutive measurements on a given blood sample. Different samples were used (table 1). The visual monocyte count has a low precision, mainly due to the small number of cells (usually not more than 100 or 200 leucocytes) identified routinely in this procedure. When 800 leucocytes are counted on a blood sample containing $5-10 \%$ monocytes, a satisfactory precision is reached (table 1 , fig 1). Higher precision should be reached with methods counting a much larger number of events. As seen in table 1, acceptable values (coefficients of variation between $5 \%$ and $12 \%$ ) were obtained with most instruments, with the notable exception of the Toa Sysmex E-5000.

The comparison between the monocyte count, as measured with the NCCLS reference method and with each of the instruments is given in figs $2 \mathrm{~A}-\mathrm{G}$.

Table 2 shows the results of the orthogonal regression analysis of the monocyte count measured by each instrument and compared with the visual count used as reference method.

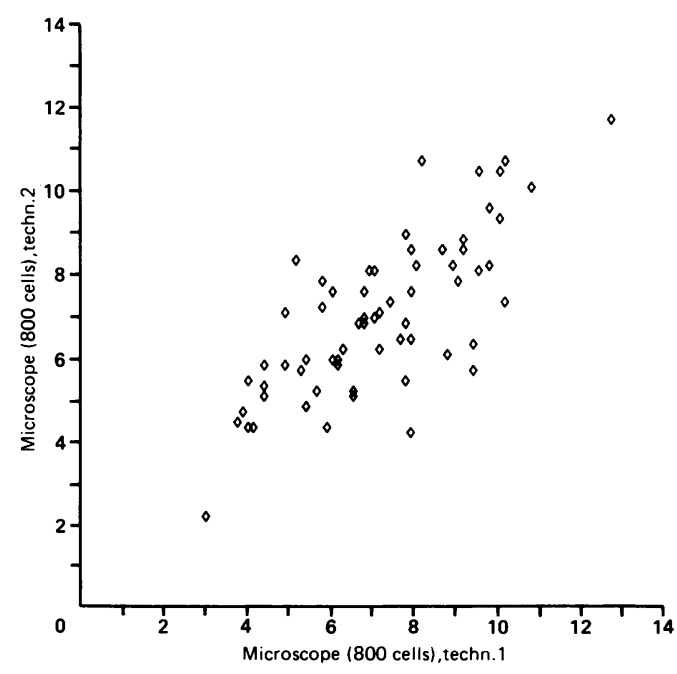

Figure 1 Comparison of monocyte count (\% of leucocytes) done by two separate technicians. They identified 800 leucocytes in 65 blood samples. Orthogonal regression analysis: slope: 0.902 , intercept:0.602, correlation coefficient: $0 \cdot 758$. 
Table 2 Orthogonal regression computed between result of each tested instrument $(y$-axis) and reference method ( $x$-axis)

\begin{tabular}{lccrl}
\hline & $N=$ & Slope & Intercept & $\begin{array}{l}\text { Correlation } \\
\text { coefficient }\end{array}$ \\
\hline Becton Dickinson FACScan & 109 & 1.080 & -1.046 & $\mathbf{0 . 8 3 0}$ \\
Coulter-VCS & 60 & 0.763 & -0.861 & 0.871 \\
Coulter S Plus IV & 109 & 1.548 & -5.294 & 0.575 \\
Ortho ELT 1500 & 155 & 1.303 & 0.205 & 0.782 \\
Technicon H1 & 109 & 0.859 & -0.611 & 0.766 \\
Toa Sysmex E-5000 & 136 & 0.852 & 3.468 & 0.289 \\
Toa Sysmex NE-8000 & 109 & 0.237 & 1.908 & $\mathbf{0 . 2 0 3}$ \\
\hline
\end{tabular}

Toa Sysmex E-5000
Toa Sysmex NE-8000

Discussion

Our results show discrepancies between the monocyte counts from normal blood samples obtained by different cell counting systems.

Cell counters, claiming to give a full differential with a specific monocyte count, use a combination of detection principles for cell identification. In contrast, systems discriminating only among three cell populations, rely on single physical detection principles.

Instruments claiming to give a specific monocyte count are thus expected to give better correlation with the "true" monocyte count (table 2). Such satisfactory correlation was seen using the FACScan, with two monoclonal antibodies (fig 2A). The Technicon $\mathrm{H} 1$ (fig 2E), and the Coulter VCS (fig 2B) also showed a satisfactory correlation, but both methodologies underestimated the result. Poor results were seen with the Toa Sysmex NE8000 (fig 2G).

Instruments measuring only a "third population" of white cells can be expected to give a higher value (including non-monocytes in their result) and to show a lower correlation with the true monocyte count (table 2). The Ortho ELT-1500, however, although overestimating the monocyte count, gave results that correlated well with our reference method (fig 2D). The third population measured with the Coulter S Plus IV shows a rather poor correlation (fig $2 \mathrm{C}$ ). The results of the Toa Sysmex E-5000 showed an even poorer correlation (fig 2F).

The described problems are partly due to the lack of a generally accepted, sufficiently accurate, and reproducible reference method for monocyte counting. We have used the visual differential as a reference, but we are aware of the subjectivity of the method. In addition, the low percentage of monocytes present in normal blood neccessitates counting a large number of leucocytes to reach acceptable confidence limits for the monocyte count. This makes the NCCLS H20-T recommended method extremely time consuming and
Figure 2 Graphical representation of results of monocyte count $(\%$ of leucocytes) comparing results obtained with different instruments ( $y$-axis) and the visual reference method ( $x$-axis). (A) Becton Dickinson FACScan; (B) Coulter VCS; (C) Coulter S Plus IV 3diff; (D) Ortho ELT1500.
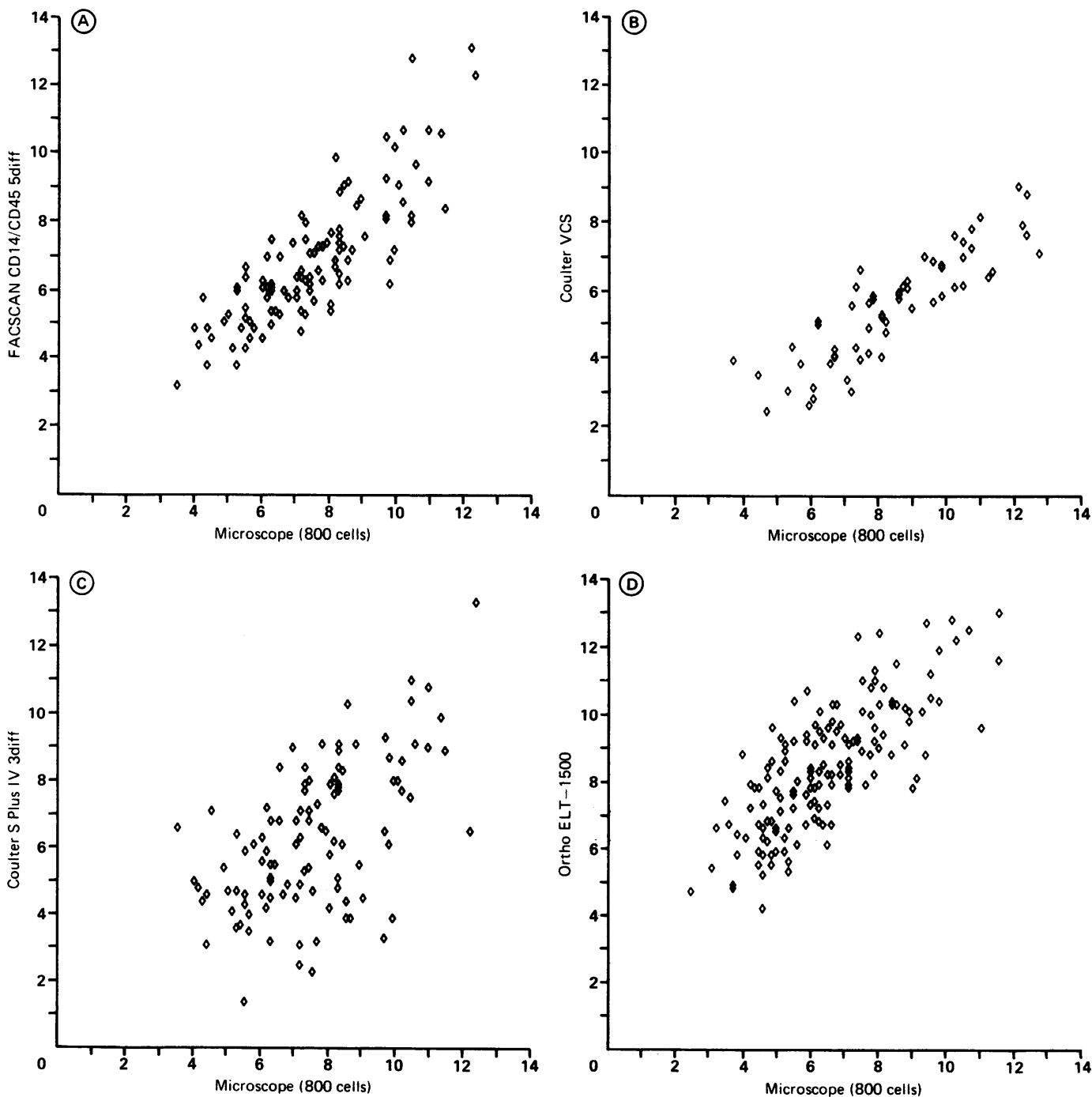
Figure 2 Graphical representation of results of monocyte count ( $\%$ of leucocytes) comparing results obtained with different instruments (y-axis) and the visual reference method ( $x$-axis). (E) Technicon $H 1$; $(F)$ Toa Sysmex E-5000; (G) Toa Sysmex NE-8000.
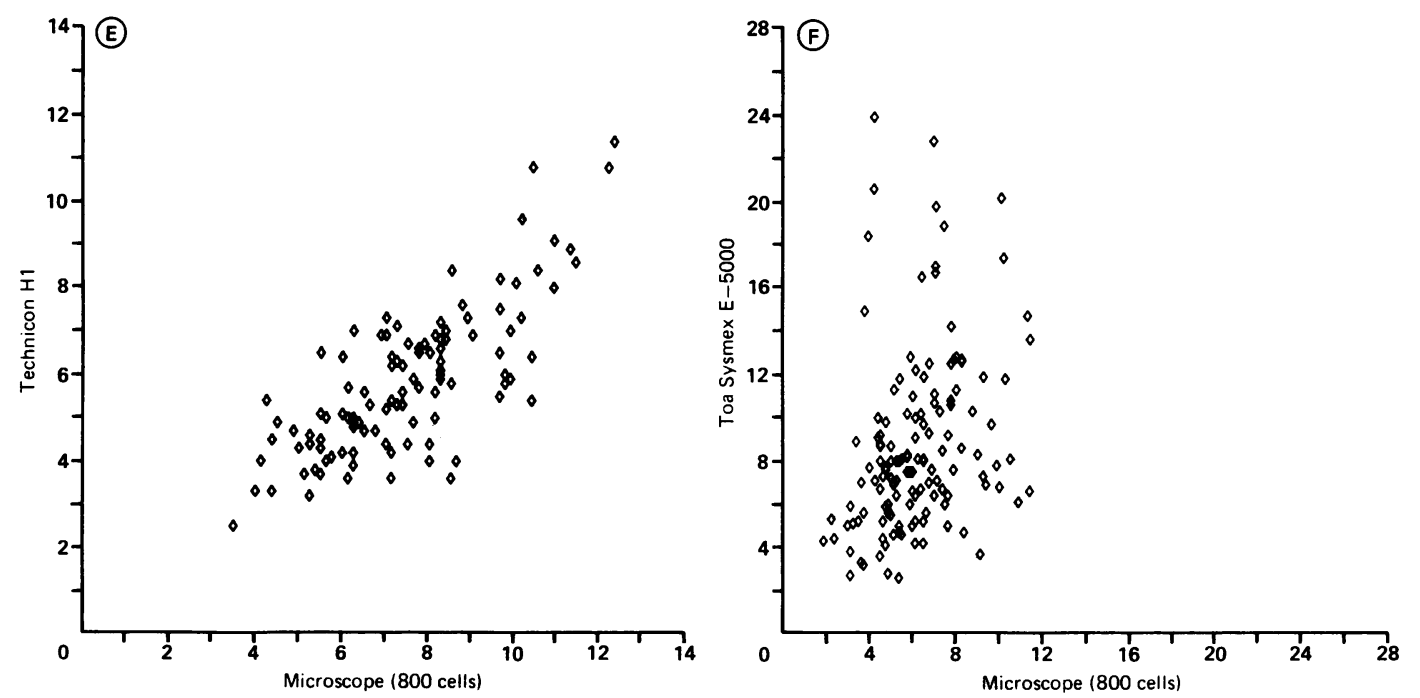

unreliable in the lower normal monocyte range. We suggest that a different method should be selected as a reference for the monocyte count. In our experience the use of monoclonal antibodies seems, at present, to be the best practical solution.

We thank $S$ Engels, $K$ Hens, $V$ Van Duppen, $M$ Van Ingelgom, $R$ Vissers and $L$ Waumans for their assistance.
1 Bennett JM, Catovsky D, Daniel MT, et al. Proposals for the classification of the myelodysplastic syndromes. Br J

2 Deming WE. Exercises on fitting various functions. In: Statistical adjustment of data. New York: John Wiley and Sons. 1943:184.

3 Cornbleet PJ, Gochman N. Incorrect least-squares regression coefficients in method-comparison analysis. Clin Chem 1979;25:432-8.

4 National Committee for Clinical Laboratory Standards. Leucocyte differential counting: Tentative standard $\mathrm{H} 20$ T. Villanova: NCCL, 1984

5 Dacie JV, Lewis SM, eds. Preparation and staining methods for blood and bone marrow films. In: Practical haematology. New York: Churchill Livingstone, 1984:52. 6 Bain BJ, ed. Morphology of blood cells. In: Blood cells: A practical guide. Philadelphia: JB Lippincott Company, 